\title{
Mechanical Properties of Thermomechanically-Processed Metastable Beta Ti-Nb-Zr Alloys for Biomedical Applications
}

\author{
Vladimir Brailovski $^{1, a}$, Sergey Prokoshkin ${ }^{2, b}$, Karine Inaekyan ${ }^{1, c}$, Sergey \\ Dubinskiy ${ }^{1,2, \mathrm{~d}}$, Maxime Gauthier ${ }^{3, \mathrm{e}}$
}

\author{
${ }^{1}$ Ecole de technologie superieure, 1100 Notre-Dame Street West, Montreal (Quebec), H3C \\ $1 \mathrm{~K} 3$ Canada \\ ${ }^{2}$ National University of Science and Technology "MISIS", 4 Leninskiy prosp., Moscow \\ 119049, Russian Federation \\ ${ }^{3}$ Industrial Materials Institute (IMI), NRC-Canada, 75, de Mortagne, Boucherville (Quebec) \\ J4B 6 Y4 Canada \\ avbrailovski@etsmtl.ca, bprokoshkin@tmo.misis.ru, ckarine.inaekyan@etsmtl.ca, \\ ${ }^{d}$ sergey.dubinskiy@ens.etsmtl.ca, ${ }^{e}$ maxime.gauthier@imi.cnrc-nrc.gc.ca
}

Keywords: shape memory alloys, titanium alloys, thermomechanical processing (TMP), biomedical applications

\begin{abstract}
Metastable beta-titanium alloys combine exceptionally low Young's modulus and high biocompatibility, thus attracting special interest in the prospect of their application as biomedical implant material. In this work, Ti-21.8Nb-6Zr (at.\%) ingots were manufactured by vacuum argon melting followed by hot isothermal pressing. The obtained ingots were thermomechanically processed using the following TMP sequence: a) cold rolling (CR) from $\mathrm{e}=0.37$ to 2 of the logarithmic thickness reduction; and b) post-deformation annealing (PDA) of between 450 and $700^{\circ} \mathrm{C}\left(10^{\prime} \ldots .5 \mathrm{~h}\right.$ for $600^{\circ} \mathrm{C}$ and $1 \mathrm{~h}$ for other temperatures). The influence of the TMP on the alloy's mechanical properties under static and cyclic loading was studied.
\end{abstract}

\section{Introduction}

The need for a metallic implant material combining superelasticity with biocompatibility comparable to that of pure titanium represents the main incentive for ongoing research in the field of $\beta$-type Ti-based superelastic alloys. Ternary and quaternary Ti-Nb-based alloys have been extensively investigated over the last several years and the results confirm the possibility of producing $\mathrm{Ni}$-free, Ti-based alloys with superelasticity thanks to reversible $\beta$ to $\alpha^{\prime \prime}$ martensitic transformation [1]-[3]. These materials have joined the family of the previously-developed lowmodulus near- $\beta$ and $\beta$-type titanium alloys containing non-toxic elements such as $\mathrm{Nb}$, $\mathrm{Ta}$, and $\mathrm{Zr}$, but without superelasticity [4], [5]. These alloys have a low elastic modulus because the elastic modulus of their body-centered cubic (bcc) $\beta$ phase is lower than that of the hexagonal close-packed (hcp) $\alpha$ phase.

Efforts to alloy binary Ti-Nb alloys with a third element, such as $\mathrm{Ta}$ or $\mathrm{Zr}$ are undertaken with the objectives of stabilizing the $\beta$ phase at room temperature, to create conditions of $\alpha^{\prime \prime}$-phase formation, to decrease the Young modulus, and to promote solid solution hardening, thereby improving the Ni-free titanium alloys' shape memory properties [6], [7]. This work studies the mechanical and functional properties of Ti-21.8Nb-6Zr (at.\%) alloy as a function of various thermomechanical processing conditions. 


\section{Materials and methods}

Ti-21.8Nb-6Zr (at.) ingots ( $50 \mathrm{~mm}$ diameter, $660 \mathrm{~mm}$ long) were manufactured by Flowserve Corp. (USA). The Vacuum Arc Remelting (VAR)-prepared ingots were subjected to Hot Isostatic Pressing (HIP) prior to delivery (for the impurity content see Tables 1).

Table 1 Impurity content of Ti-21.8Nb-6Zr ingots (Flowserve, USA)

\begin{tabular}{|l|l|c|c|c|c|c|}
\hline (b) & Elements & Fe & O & C & N & H \\
\cline { 2 - 7 } & Content, wt\% & 0.04 & 0.13 & 0.01 & 0.01 & 0.007 \\
\hline
\end{tabular}

The ingots were EDM-cut in 1x1.5x100 (mm) samples (reference treatment, recrystallized $\beta$-phase state) and then subjected to different thermomechanical processing (TMP) sequences including: a) cold rolling $(\mathrm{CR})$ at $\mathrm{e}=0.37,0.75,1.14,1.65$ and 2 of the logarithmic thickness reduction, and $\mathrm{b}$ ) post-deformation annealing (PDA) at $450,500,550,600$ and $700^{\circ} \mathrm{C}\left(10^{\prime} \ldots 5 \mathrm{~h}\right.$ for $600^{\circ} \mathrm{C}$ and $1 \mathrm{~h}$ for other temperatures).

The experimental methodology featured two sequential steps, each with a specific objective. The first step was designed to determine the most favorable TMP conditions for the selected alloy (optimization), and the second step was to apply these conditions to the alloy samples and carry out their detailed thermomechanical characterisation.

Optimization.

As our goal was to find the best-suited TMP conditions, we limited the number of variables to the following three: CR thickness reduction, PDA temperature, and time. The upper and low bounds for all the variables were established based on preliminary results. The specimens subjected to different TMP routes were cyclically tested (loading-unloading) at RT on MTS' MiniBionix by applying a constant $2 \%$ tensile strain during each cycle up to specimen failure. The stress-strain tensile diagrams were then compared using two interrelated criteria: the closeness of their mechanical behavior to the conventional superelasticity and the number of cycles to failure.

The following three-step shortest-path optimization approach was applied to optimize TMP conditions for a given alloy:

1. Specimens were thermally treated at different temperatures ranging from 450 to $700^{\circ} \mathrm{C}(1 \mathrm{~h})$ to select an optimum PDA temperature.

2. Specimens were cold-rolled with different thickness reductions from $\mathrm{e}=0.37$ to 1.65 , and annealed at the optimum PDA temperature (Point 1) to select an optimum thickness reduction.

3. Specimens were cold-rolled with optimum thickness reduction (Point 2) and annealed at the optimum PDA temperature (Point 1) for variable times (from 10' to $5 \mathrm{~h}$ ) to select an optimum annealing time.

\section{Characterization}

To characterize Ti-21.8Nb-6Zr alloy subjected to the optimized TMP, two types of tests were performed and their results compared: a) isothermal tensile loading-unloading and b) constant-strain temperature scanning. Both tests were carried out on a customized LAMSI testing bench [8]. The force and displacement were measured by a load cell (60001-750lbs, Omega) and an LVDT (Trans Tek series 240) using Labview 8.5 software (National Instrument).

Isothermal tensile testing up to $2 \%$ strain was carried out at $-140,-110,-75,-35,0,25,40,60,100$ and $150^{\circ} \mathrm{C}$. This test consisted of a ten-cycle constant-strain cyclic loading-unloading followed by monotonous tension up to specimen failure.

Constant-strain temperature scanning testing was conducted as follows: samples were installed on the testing bench at RT, cooled down to $-140^{\circ} \mathrm{C}$, stretched up to strains of 1,2 and $3 \%$ and finally heated up to $250^{\circ} \mathrm{C}$. 


\section{Results}

The results of the three-step optimization procedure follow:

- Stress-strain diagrams of thermally treated reference specimens (reference, 450,600 and $700^{\circ} \mathrm{C}$, all $1 \mathrm{~h}$ ) are presented in Fig. 1a,b,c,d. From the comparative analysis of the diagrams, $600^{\circ} \mathrm{C}$ annealing temperature is selected for the subsequent step. This conclusion is supported by the results of tensile testing after different CR intensities followed by PDA (Fig. 2), where for all the $\mathrm{CR}$ intensities tested, a minimum of transformation stress and maximum ductility were obtained after $600^{\circ} \mathrm{C}$ PDA (see also [7]).

- Stress-strain diagrams of reference specimens subjected to cold rolling with different thickness reductions $(\mathrm{e}=0.37,0.75,1.14$ and 1.65$)$ and then annealed at $600^{\circ} \mathrm{C}$ PDA $(1 \mathrm{~h})$ are presented in Fig. 1e,f,g,h. From the comparative analysis of the diagrams, the thickness reduction of e $=0.37$ is selected for the subsequent step.

- Stress-strain diagrams of the reference specimens subjected to $\mathrm{CR}(\mathrm{e}=0.37)$ and post-deformation annealing $\left(600^{\circ} \mathrm{C}\right)$ for different times $\left(10^{\prime}, 20^{\prime}, 30^{\prime}, 1\right.$ and $\left.5 \mathrm{~h}\right)$ are presented in Fig.3 a,b,c,d,e. From a comparative analysis of the diagrams, the 30' annealing time is selected as the optimum annealing time.

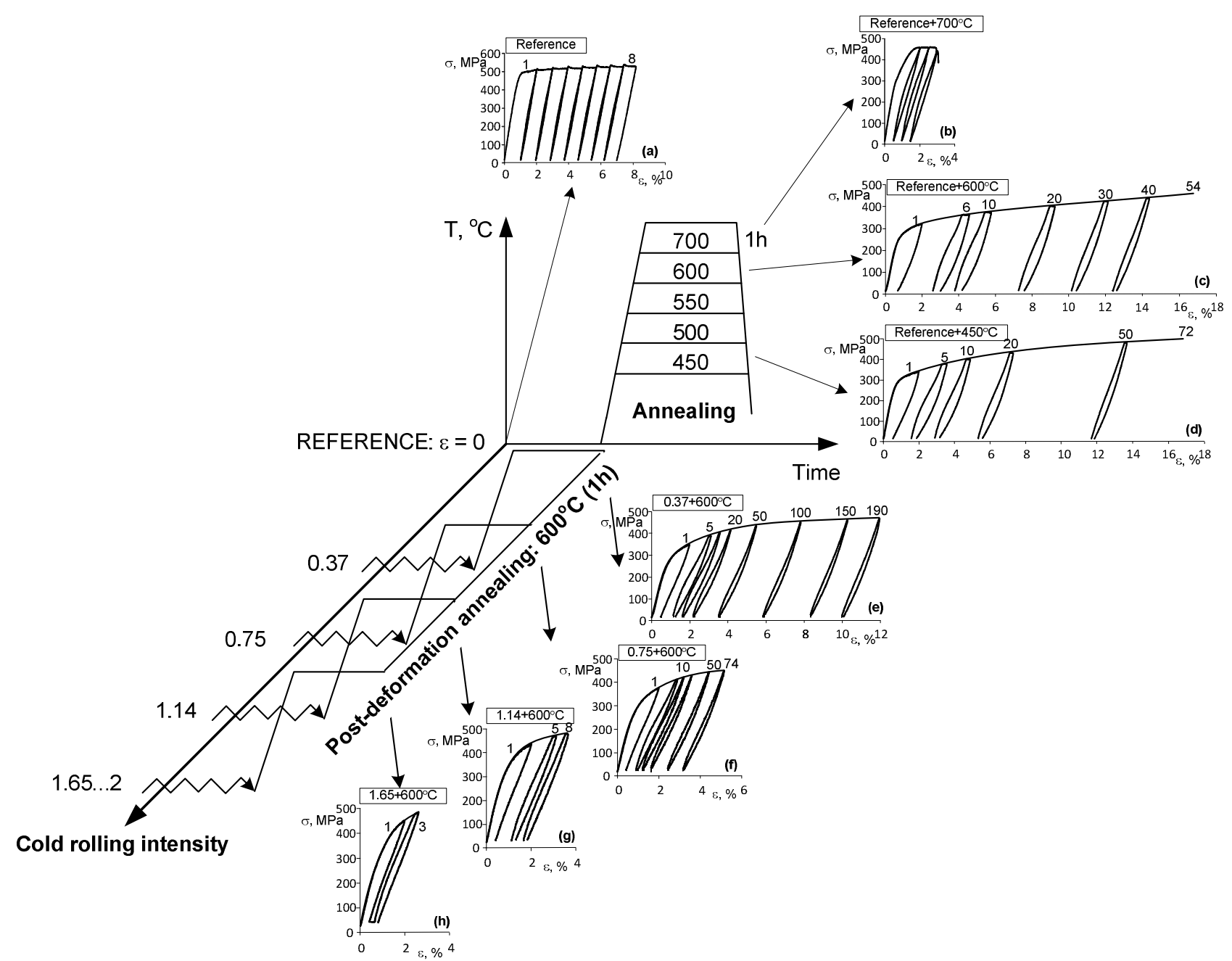

Fig. 1. Stress-strain diagrams of specimens subjected to variable PDAs (a,b,c,d) and CRs (e,f,g,h); $\varepsilon$ is accumulated strain 

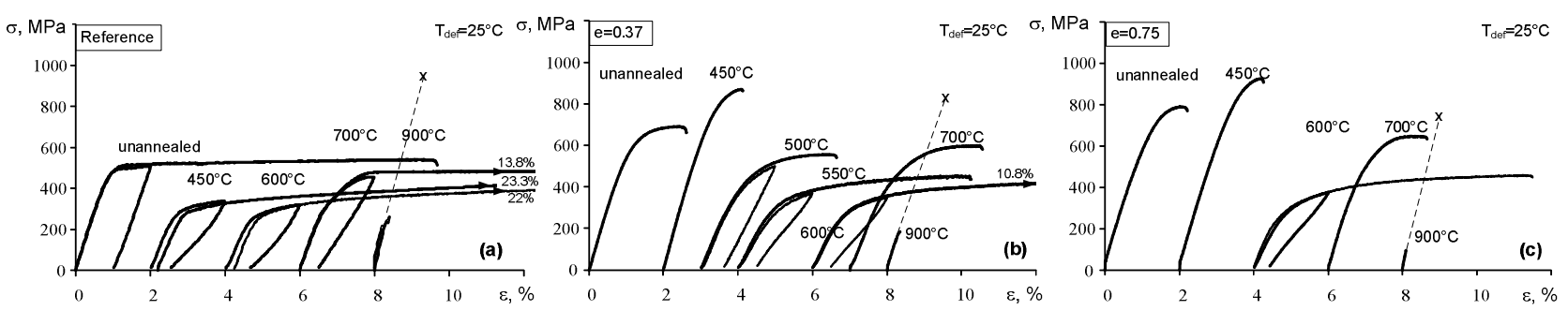

Fig. 2. Stress-strain diagrams after different PDAs for (a) reference, (b) e $=0.37$ and (c) e $=0.75$

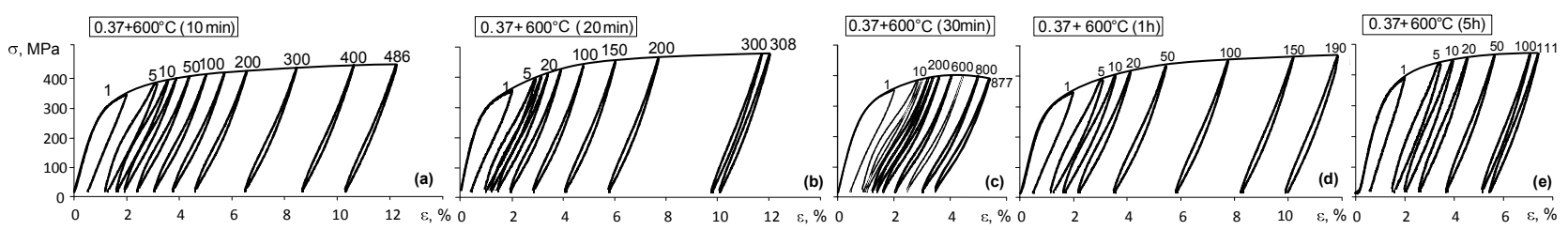

Fig. 3. Stress-strain diagrams of specimens subjected to variable-time annealing at $600^{\circ} \mathrm{C}$ for (a) 10 ; (b) 20'; (c) 30'; (d) 1h; (e) 5h; $\varepsilon$ is accumulated strain

For the subsequent characterization, the following TPM sequence was selected: $\mathrm{CR}(\mathrm{e}=0.37)$ followed by PDA $\left(600^{\circ} \mathrm{C}, 30^{\prime}\right)$.

Isothermal tensile test

A series of stress-strain diagrams obtained at different temperatures is presented in Fig. 4. In Fig. 5, constant-strain temperature scanning test results are plotted for 1, 2 and 3\% initial strains. The values of transformation stresses and Young's modulus retrieved from isothermal stress-strain diagrams of Fig. 4 are also superposed on Fig. 5 as a function of testing temperature. Note that direct comparison of Young's moduli obtained from the Fig. 1-Fig.3 and from Fig. 4-Fig. 5 stressstrain diagrams can be deceiving because they were obtained with different equipment (an MTS MinBionix and a LAMSI bench, respectively) with different frame rigidity. The use of an extensometer was not possible at low temperatures, which resulted in underestimation of the Young's modulus values in the lower rigidity LAMSI bench. However, this does not compromise the trends observed in this study.

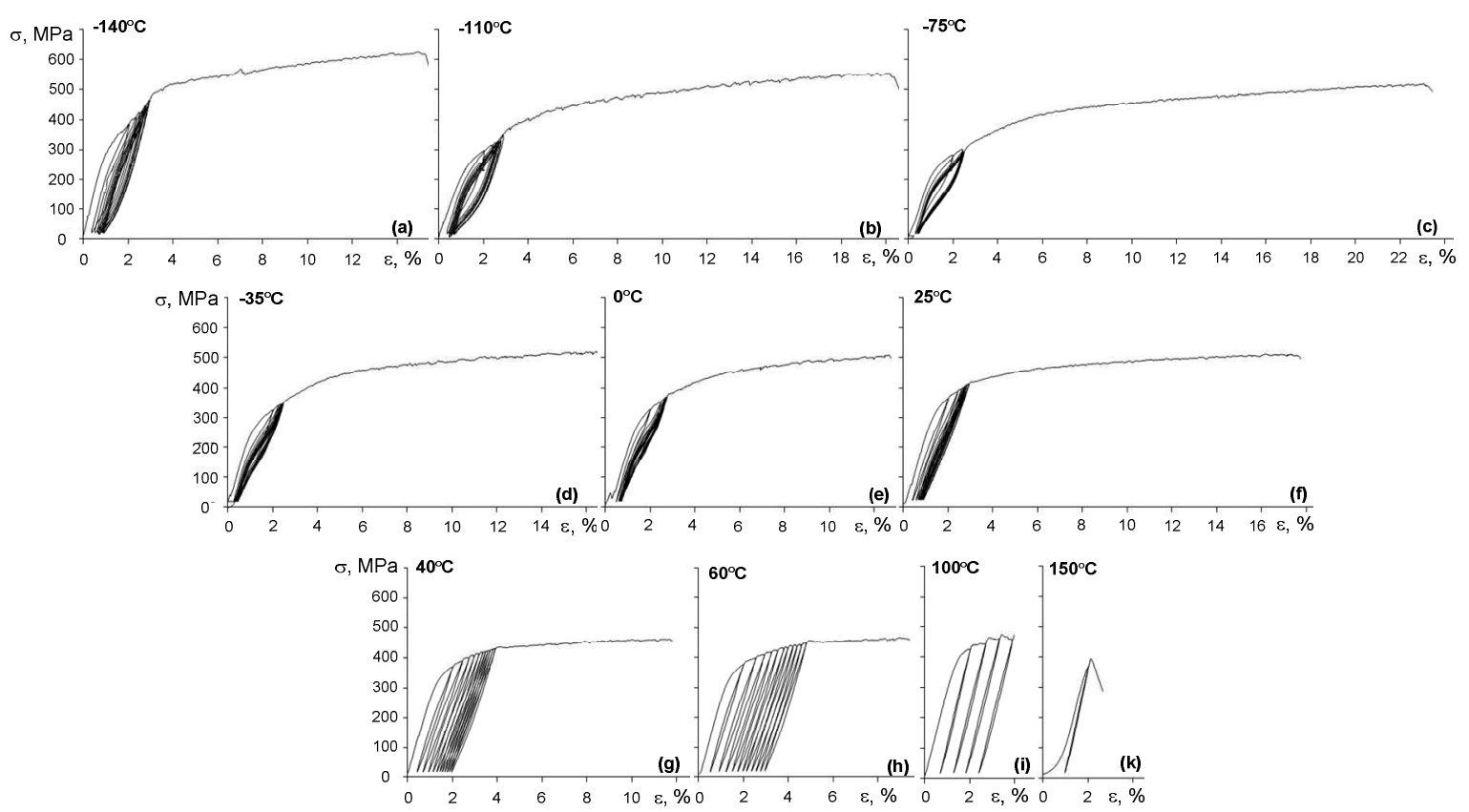

Fig. 4. Isothermal stress-strain diagrams at (a) $-140^{\circ} \mathrm{C}$, (b) $-110^{\circ} \mathrm{C}$, (c) $-75^{\circ} \mathrm{C}$, (d) $-35^{\circ} \mathrm{C}$, (e) $0^{\circ} \mathrm{C}$, (f) $25^{\circ} \mathrm{C}$, (g) $40^{\circ} \mathrm{C}$, (h) $60^{\circ} \mathrm{C}$, (i) $100^{\circ} \mathrm{C}$, (k) $150^{\circ} \mathrm{C}$ 


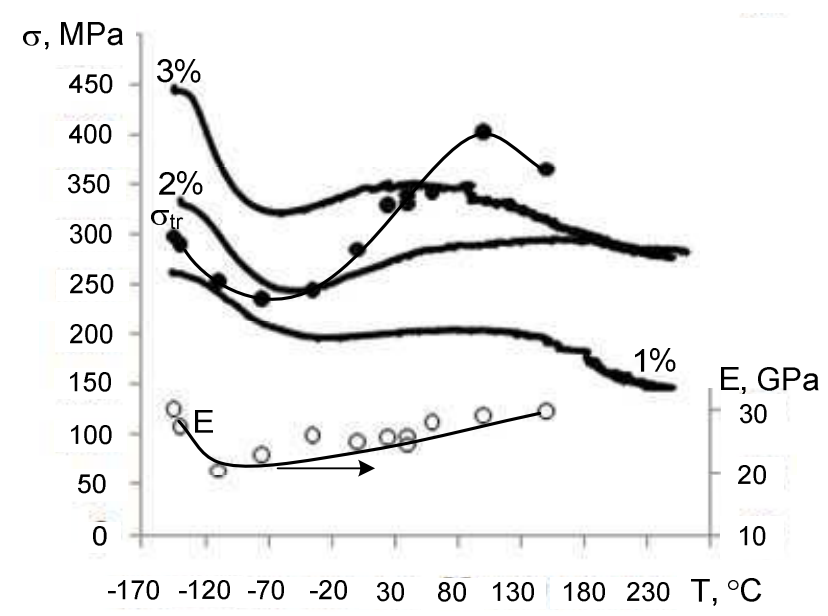

Fig. 5. Constant-strain temperature scanning diagrams for 1, 2 and $3 \%$ strains, as well as transformation yield stress and Young's moduli from Fig.4.

\section{Discussion}

It was observed that PDA at $600^{\circ} \mathrm{C}(1 \mathrm{~h})$ of the reference specimens $(\mathrm{e}=0)$ yields the lowest transformation stress in the alloy (Fig. 1c). Furthermore, the higher the CR intensity, the higher the transformation stress and the lower the alloy's cyclic life (Fig. 2e,f,g,h). Cold rolling intensity of $\mathrm{e}=0.37$ however results in the best combination of the low transformation stress and high number of cycles at failure (Fig. 1e). The longest fatigue life and perfectly superelastic behavior are observed after $\mathrm{CR}$ of $\mathrm{e}=0.37$ and PDA of $600^{\circ} \mathrm{C}, 30^{\prime}$ (Fig. $3 \mathrm{c}$ ), and these processing conditions are considered as the optimum TMP. This TMP sequence corresponds to a polygonized nanosubgrained structure in $\beta$-phase with average subgrain size somewhat below $100 \mathrm{~nm}$ (see [9] for a detailed microstructural analysis).

From the results of the isothermal tensile testing, testing temperature of $\mathrm{T}=-75^{\circ} \mathrm{C}$ corresponds to the perfectly superelastic stress-strain diagrams with the lowest transformation stress and Young's modulus, and the highest elongation to failure among all the testing temperatures (Fig. 4).

This testing temperature coincides with the temperature of the overall alloy softening, as observed during the temperature scanning test (see Fig. 5). For example, from the constant-strain (3\%) temperature scanning diagram, when the testing temperature increases from -140 to $-70^{\circ} \mathrm{C}$, the stress decreases from 450 to $320 \mathrm{MPa}$. However, when the temperature continues to rise, the stress increases to reach $350 \mathrm{MPa}$ at $50^{\circ} \mathrm{C}$ and then decreases again.

Before heating, the stretched specimen is in the two-phase $(\alpha$ ' $+\beta)$ state. The first decrease in stress upon heating (Fig. 5) represents a combined result of thermal dilatation of the two-phase material and of the $\alpha$ ' lattice softening under stress in the vicinity of the $\alpha$ ' $\leftrightarrow \beta$ transformation temperature. While the first phenomenon is dominant at lower temperatures (between -140 and $-130^{\circ} \mathrm{C}$ ), the second becomes preeminent at higher temperatures (between -130 and $-70^{\circ} \mathrm{C}$ ). When the temperature increases further, the stress rises because of the constrained recovery stress generation. The second stress decrease seems to be caused mainly by thermal dilatation of the $\beta$-phase. Both the softening-hardening temperatures and corresponding stresses depend on the initial strain: the higher the initial strain, the more drastic the first softening as a function of temperature $(\Delta \sigma / \Delta T)$ and the more abrupt the subsequent hardening.

Following studies carried out in Miyazaki's lab [6], the main elements' content of the studied alloy (Ti-21.8Nb-6Zr, at.\%) should have led to perfect superelasticity since the first cycle of testing at human body temperature, which is obviously not the case here (Fig. 4). This discrepancy can be explained by the presence of certain impurities, more specifically oxygen (see Table 1). Efforts should be made to adjust both the composition and the melting conditions to significantly raise the superelasticity temperature window of the studied alloy. 
If stress-strain diagrams obtained at -75 and $40^{\circ} \mathrm{C}$ are directly compared (Fig. 6), one can conclude that the $-75^{\circ} \mathrm{C}$ conditions are superior, and not only in respect to perfect superelasticity observed at that temperature, but also because of a greater difference between the transformation, true yield and ultimate tensile stresses, as well a larger elongation to failure in this case. These differences suggest that if the alloy is tested at $-75^{\circ} \mathrm{C}$, it would demonstrate greater toughness than at $40^{\circ} \mathrm{C}$, which is of paramount importance for biomedical applications.

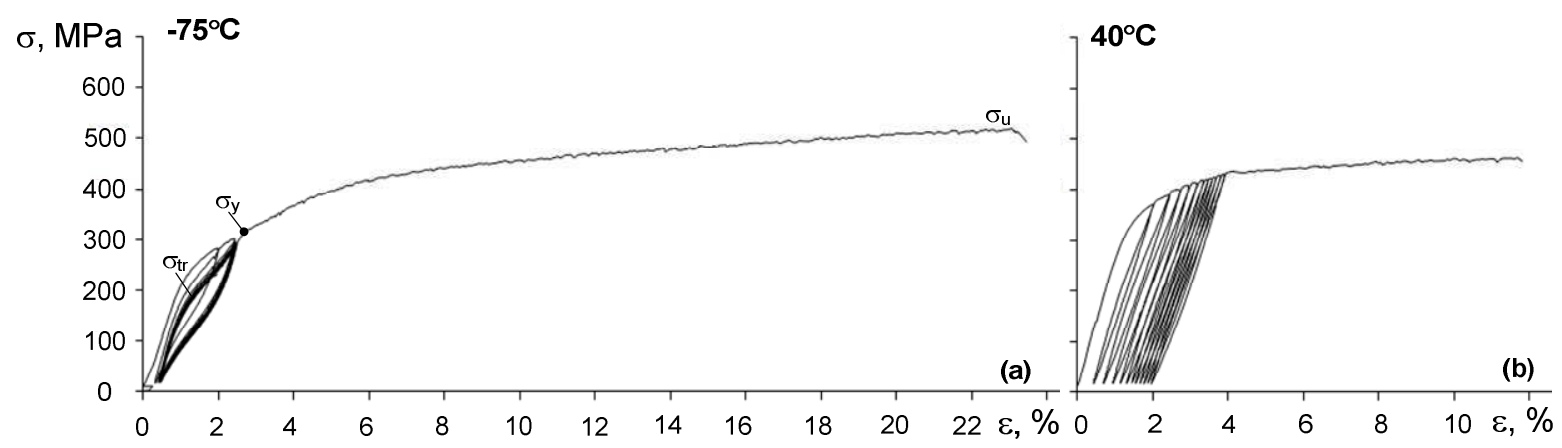

Fig. 6. Stress-strain diagrams of Ti-21.8Nb-6Zr alloy corresponding to: (a) temperature of perfect superelasticity and (b) human body temperature

\section{Conclusions}

1. From this study, the best TMP conditions for $\mathrm{Ti}-21.8 \mathrm{Nb}-6 \mathrm{Zr}$ (at $\%)$ alloy are: $\mathrm{CR}(\mathrm{e}=0.37$ of thickness reduction) followed by PDA $\left(600^{\circ} \mathrm{C}, 30^{\prime}\right)$. These TMP conditions can produce a material with almost perfect superelastic behavior (2\% of reversible strain) and about 900 cycles of cyclic life under stringent conditions of accumulated-strain tension testing ( $2 \%$ per cycle).

2. From the isothermal tensile testing and constant-strain thermal scanning testing in the $-150 \ldots$ $+200^{\circ} \mathrm{C}$ range, it appears that significant materials softening occurs at $-75^{\circ} \mathrm{C}$ as a result of $\alpha " \leftrightarrow \beta$ martensitic transformation. This temperature corresponds to a perfect superelastic behavior combined with the highest elongation to failure $(23 \%)$.

\section{Acknowledgments}

This work was supported by the Ministry of Economic Development of Quebec, the National Science and Engineering Research Council of Canada and the Ministry of Education and Science of the Russian Federation.

\section{References}

[1] H. Kim, Y. Ikehara, J. Kim, H. Hosoda, S. Miyazaki: Acta Mater. Vol. 54(9) (2006), p. 2419.

[2] Y.L. Hao, S.J. Li, S.Y Sun, C.Y. Zheng, Q.M. Hu, R. Yang: Appl. Phys. Lett. Vol. 87(9) (2005), p. 091906.

[3] S.J. Li, T.C. Cui, Y.L. Hao, R. Yang: Acta Biomater. Vol 4 (2008), p. 305.

[4] A.K. Mishra, J.A. Davidson, P. Kovacs, R.A. Poggie, in: Beta Titanium in the 1990's, edited by D. Eylon, R. Boyer, D. Koss, Warrendale, PA: TMS, (1993).

[5] M. Niinomi: Biomater. Vol. 24 (2003), p. 2673.

[6] S. Miyazaki, H.Y. Kim, H. Hosoda: Mater. Sci. Eng. A Vol. 438-440 (2006), p. 18.

[7] V. Brailovski, S. Prokoshkin, M. Gauthier, K. Inaekyan, S. Dubinskiy, M. Petrzhik and M. Filonov: Mater. Sci. Eng. C, Vol. 31 (2011), p. 643.

[8] V. Demers, V. Brailovski, S.D. Prokoshkin, K.E. Inaekyan: Mater. Sci. Eng. A Vol. 513-514 (2009), p. 185

[9] S. Prokoshkin, V, Brailovski, K. Inaekyan, A. Korotitskiy, S. Dubinskiy, M. Filonov and M. Petrzhik: Thermec 2011 Proceedings, in press. 